\title{
PRODUÇÃO CIENTÍFICA SOBRE GESTÃO DO CONHECIMENTO E GESTÃO DA INFORMAÇÃO NO ÂMBITO DA CIÊNCIA DA INFORMAÇÃO: UMA APLICAÇÃO DA LEI DE BRADFORD
}

\author{
Mariana Lousada* \\ Universidade Estadual Paulista. Brasil. \\ Cristiane Luiza Salazar Garcia** \\ Universidade Estadual Paulista. Brasil. \\ Luana Maia Woida ${ }^{* * *}$ \\ Universidade Estadual Paulista. Brasil. \\ Paula Dal' Evedove \\ Universidade Estadual Paulista. Brasil. \\ Regis Garcia ${ }^{* * * * *}$ \\ Universidade Estadual Paulista. Brasil. \\ Marta Lígia Pomim Valentim ${ }^{* * * * *}$ \\ Universidade Estadual Paulista. Brasil.
}

\begin{abstract}
Resumo: Objetivou-se analisar a produção científica sobre gestão da informação e gestão do conhecimento nos periódicos mais relevantes da área de Ciência da Informação, observando assim a relevância e impacto destes para esta área de conhecimento. A pesquisa, de caráter quantitativo, analisou a produção científica sobre essa temática publicada nos periódicos com acesso online da área de Ciência da Informação classificados no Qualis da Coordenação de Aperfeiçoamento de Pessoal de Nível Superior (CAPES), mais especificamente os que foram avaliados como de nível 'A' e 'B', abrangendo um total de 26 títulos de periódicos. Aplicou-se a Lei de Bradford para a análise da produção científica, especialmente em relação à distribuição dos artigos em termos de variáveis de proximidade ou de afastamento. Observou-se que os termos 'gestão da informação' e 'gestão do conhecimento' são contemporâneos e ganham relevância ao longo do tempo. Evidenciou-se, também, que a regra geral de que "poucos autores produzem muito e muitos autores
\end{abstract}

\footnotetext{
*marianalousada@hotmail.com

** cris_luiza_salazar@hotmail.com

***luanamwoida@yahoo.com.br

****sud_dove@yahoo.com.br

***** regis.garcia@shmaraba.com.br

******valentim@valentim.pro.br
}

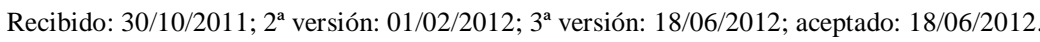

LOUSADA, M. et al. Produção científica sobre gestão do conhecimento e gestão da informação no âmbito da ciência da informação: uma aplicação da Lei de Bradford. Anales de Documentación, 2012, vol. 15, $\mathrm{n}^{\circ} 2$. ISSN: 1697-7904. http://dx.doi.org/10.6018/analesdoc.15.2.138741. 
produzem pouco" é verdadeira se consideradas as características da distribuição dos dados pesquisados.

Palavras chave: Lei de Bradford; produção científica; gestão da informação; gestão do conhecimento.

Title: PRODUCTION OF SCIENTIFIC KNOWLEDGE MANGEMENT AND INFORMATION MANAGEMENT IN SCOPE OF INFORMATION SCIENCE: AN APPLICATION OF THE LAW OF BRADFORD.

Abstract: Aimed to analyze the scientific literature on information management and knowledge management in the most relevant journals in the Information Science field, noting in this way then relevance and impact to this field. It is a qualitative research and analyzed the scientific literature about this subject published in journals (online access) in the Information Science area and classified as Qualis of Coordenação de Aperfeiçoamento de Pessoal de Nível Superior (CAPES), specifically those who were assessed as level 'A' and 'B', covering a total of 26 journal titles. We applied the Bradford's Law for the scientific production analysis, especially in relation to the articles distribution in terms of proximity or distance variables. We observed that the terms 'information management' and 'knowledge management' are contemporary and have been gained relevance over time. We also founded that the general rule: "few produces a lot and many produces a little" is true if considered the characteristics of the studied data distribution.

Keywords: Bradford Law; scientific production; information management; knowledge management.

\section{INTRODUÇÃO}

A Ciência da Informação (CI) passa a ser compreendida como campo científico por volta da Década de 60. Com essa curta trajetória, ainda hoje discute sobre seu objeto, a informação, no intuito de mais bem compreender suas raízes e, assim, construir uma sólida estrutura apoiada em seus fundamentos. Como uma área interdisciplinar, a CI interage com outras áreas do saber, formando um amplo escopo de investigação e atuação.

A gestão da informação (GI) e a gestão do conhecimento (GC) passam a integrar as preocupações teóricas e práticas da área de CI e, portanto, a própria história desta área, por volta da Década de 80. A partir das influências advindas das Ciências Administrativas, a GI e a GC interagem com a área de Ciência da Informação, formando uma aliança que vai se consolidando de forma crescente. Compreender como se relacionam, bem como entender sua influencia sobre a área, é fundamental para a consolidação do campo científico.

Uma das principais referências desse aproveitamento de conceitos próprios à gestão pela CI pode ser verificada em estudos bibliométricos, por meio da aplicação de indicadores como a Lei de Bradfort, voltados a mensurar a produção científica.

Machado (2007) demonstra que em dezesseis anos de pesquisa envolvendo a temática sobre Bibliometria no Brasil, de vinte e um artigos selecionados apenas dois (10\%) envolviam diretamente a aplicação da Lei de Bradford. 


\begin{tabular}{|c|c|c|c|c|c|c|}
\hline \multirow{3}{*}{ TEMAS } & \multicolumn{4}{|c|}{ ESTUDOS } & \multicolumn{2}{|c|}{ TOTAL } \\
\hline & \multicolumn{2}{|c|}{ Teóricos } & \multicolumn{2}{|c|}{ Exploratórios } & & \\
\hline & Qtde. & $\%$ & Qtde. & $\%$ & e. Qtd & $\%$ \\
\hline Bibliometria & 7 & $70 \%$ & 2 & $18 \%$ & 9 & $43 \%$ \\
\hline Lei de Bradford & 1 & $10 \%$ & 1 & $9 \%$ & 2 & $9 \%$ \\
\hline $\begin{array}{l}\text { Análise } \quad \text { de } \\
\text { Citação }\end{array}$ & 1 & $10 \%$ & 7 & $64 \%$ & 8 & $38 \%$ \\
\hline Obsolescência & 1 & $10 \%$ & 1 & $9 \%$ & 2 & $10 \%$ \\
\hline Total & 10 & $100 \%$ & 11 & $100 \%$ & 21 & $\%$ \\
\hline
\end{tabular}

Tabela 1. Distribuição dos artigos por temas. Fonte: Machado - 2007 - p. 14.

Através da análise da literatura produzida e publicada nos periódicos de acesso online da área de Ciência da Informação no país, sobre os assuntos 'gestão da informação' e 'gestão do conhecimento', procurou-se verificar a ocorrência desses temas na produção científica, bem como sua relevância e impacto no âmbito da CI. O estudo propiciará, por meio da análise dos dados, uma melhor compreensão da influência da GI e da GC na área da Ciência da Informação, no que tange à produção científica.

\section{GESTÃO DA INFORMAÇÃ̃}

A informação especializada produzida em ambientes informacionais não convencionais permeia os interesses de áreas que ajudaram a formação da CI, como é o caso da Biblioteconomia, desde o início do Século XX. A linha de interesse regida pela Special Libraries Association ou Biblioteconomia Especializada, teve como maior precursor John Cotton Dana (SHERA, 1980, p. 91). Nesse sentido, os primórdios da formação da CI demonstram interesses e convergências teóricas importantes com os campos de estudos voltados à gestão.

Em um processo claro de aproveitamento dos conceitos aplicados aos ambientes especializados e comumente pertinentes à Biblioteconomia, a CI se apropriou de modelos de gestão cujos interesses centrais estavam depositados na informação e em como transformá-la em um recurso fundamental para os processos organizacionais, de forma que o resultado deveria ser traduzido em produto ou serviço informacional. Sendo assim, a gestão da informação, cujos pressupostos se aproximam de os defendidos pela CI, dissemina noções de que a informação registrada é fundamental no ambiente organizacional, pois pode ser identificada, coletada, organizada e recuperada. Tais pressupostos são válidos tanto para a CI quanto para a gestão da informação.

A informação registrada se destaca nesse modelo de gestão, uma vez que possibilita a existência de fluxos formais e o uso de tecnologias de informação e comunicação (TIC). Nesse contexto reside sua pertinência, isto é, não ser restrita apenas às coincidências defendidas enquanto pressupostos, mas, sobretudo, a uma noção bastante prática e funcionalista aplicada aos ambientes organizacionais. Conforme mencionado, a gestão da 
informação encontra-se amplamente amparada por ferramentas tecnológicas, o que lhe confere uma condição bastante prática. Observa-se que os interesses da CI pela gestão da informação estão presentes na produção científica existente, bem como em diversos tipos de materiais divulgados no meio científico.

As origens da gestão da informação são abordadas nos estudos de Paul Otlet em Traité de documentation, obra publicada em 1934. Diversos autores consideram esse estudo um marco fundamental para o desenvolvimento desse tema, disciplina que, na época, era conhecida como Documentação (BARBOSA, 2008, p. 6). O gerenciamento da informação envolve todos os processos relacionados à obtenção de informação adequada, de maneira correta, para a pessoa indicada, ao custo adequado, no momento oportuno, em lugar apropriado, com o objetivo de propiciar a correta tomada de decisão (WOODMAN, 1985 apud PONJUÁN DANTE, 1998, p. 135).

A principal finalidade da implantação de um programa de gestão da informação reside na identificação e na potencialização da aplicação e aproveitamento dos recursos informacionais presentes tanto no ambiente interno quanto externo à organização. De acordo com Rosseau e Couture (1998, p. 63) “[...] a gestão da informação favorece um acesso rápido e eficaz a uma informação de qualidade quer interna quer externa ao organismo". A gestão da informação é fundamental para subsidiar processos de construção de conhecimento, principalmente no âmbito organizacional. Numa economia baseada em informação, a concorrência entre as organizações baseia-se, principalmente, em sua própria capacidade de adquirir, tratar, interpretar e utilizar a informação de forma eficaz, ou seja, de maneira estratégica.

Conceitualmente entende-se a gestão informacional como:

Conjunto de atividades que visa: obter um diagnóstico das necessidades informacionais; mapear os fluxos formais de informação nos vários setores da organização; prospectar, coletar, filtrar, monitorar, disseminar informações de diferentes naturezas; e elaborar serviços e produtos informacionais, objetivando apoiar o desenvolvimento das atividades/tarefas cotidianas e o processo decisório nesses ambientes. (VALENTIM, 2004, p. 1).

Ressalta-se, ainda, que esses processos apesar de distintos são cíclicos, ou seja, a partir do momento do início do processo de gestão, as etapas subsequentes devem e necessitam ser realimentadas constantemente.

A gestão da informação acontece necessariamente a partir do conhecimento profundo dos tipos de informação que circulam dentro da organização (PONJUÁN DANTE, 2004, p. 24). Desse modo, as principais etapas de um programa de gestão da informação são:

- Identificação de Necessidades: Consiste em avaliar e identificar as necessidades informacionais dos grupos e indivíduos que fazem parte da organização e de seus parceiros externos, permitindo a elaboração de produtos e serviços informacionais direcionados especificamente às necessidades identificadas.

- Obtenção: Trata-se da definição de um plano sistemático para adquirir a informação das fontes de origem (eletrônica ou manualmente) internamente ou 
externamente, ou de forma mais detalhada, compreende as atividades de criação, recepção ou captura de informação, provenientes de fonte externa e interna, registradas em qualquer formato ou mídia (BEAL, 2008, p. 30).

- Tratamento: Normalmente as informações coletadas exigem tratamento que compreende: organização, formatação, estruturação, análise/classificação, síntese e apresentação, cuja finalidade é torná-la acessível e facilitar sua localização por parte dos usuários (BEAL, 2008, p. 30). São tarefas decorrentes ocorrendo quase que, simultaneamente.

- Distribuição/Disseminação: Busca levar a informação necessária a quem precisa dela. A distribuição envolve a mediação de gerentes e funcionários com a informação de que necessitam. Se os outros passos do gerenciamento da informação estiverem funcionando bem o processo de distribuição será satisfatório.

- Uso/Apropriação: Considerada por alguns autores como a etapa mais relevante para o processo de gestão. Essa questão é bastante discutida pela literatura. "Isto porque é algo bastante pessoal, a maneira como procura, absorve e dirige a informação antes de tomar uma decisão depende de suas características cognitivas" (DAVENPORT; PRUSAK, 1998, p. 194).

Considera-se que as etapas que apóiam o programa de gestão da informação constituem-se em um processo integrado, em que todas as etapas se conectam de alguma forma.

\section{GESTÃO DO CONHECIMENTO}

O conhecimento encontra-se presente em todos os processos e atividades e desenvolvidos pelas organizações. Por essa razão, o seu reconhecimento e gerenciamento são fundamentais para empresas que buscam diferenciais de produtividade, lucratividade e competitividade. Entende-se a gestão do conhecimento como:

Um conjunto de atividades que visa trabalhar a cultura organizacional/informacional e a comunicação organizacional/ informacional em ambientes organizacionais, no intuito de propiciar um ambiente positivo em relação à criação/geração, aquisição/apreensão, compartilhamento/socialização e uso/utilização de conhecimento [...]. (VALENTIM, 2008, p. 4).

Logo, o principal objetivo da gestão do conhecimento é gerenciar a apropriação, criação, disseminação e utilização do conhecimento necessário para que a organização possa atingir plenamente seus objetivos. Por meio da aplicação de métodos, técnicas e ferramentas busca propiciar uma cultura positiva em relação ao compartilhamento, apropriação e uso de informação, visando à construção de conhecimento.

As empresas que adotam seus preceitos buscam extrair o máximo proveito de seus bens intangíveis (capital intelectual), identificando e mapeando seus ativos intelectuais, facilitando o acesso às informações organizacionais, compartilhando experiências e tecnologia, investindo em treinamento, incentivando a criatividade e a inovação, e criando assim novos conhecimentos. Os bens intangíveis estão presentes em diferentes locais, tais 
como: base de dados, documentos produzidos e recebidos e, principalmente, no conhecimento adquirido de seus funcionários.

A adoção do programa de gestão do conhecimento organizacional pressupõe a elevação da capacidade de criação de conhecimentos, novas idéias, aprendizagem organizacional, além de subsidiar processos decisórios. De acordo com Davenport, DeLong e Beers (1998 apud SILVA, 2002, p. 145) pode-se mencionar um conjunto de indicadores para o sucesso de projetos de gestão do conhecimento:

- Não deve ser o projeto de um indivíduo, mas sim da organização;

- Desenvolver uma definição do conhecimento na empresa;

- Enfatizar o conhecimento como enfoque e fluxo;

- O conhecimento está dentro e fora da mente das pessoas;

- Criar ambientes para que o mercado de conhecimentos possa florescer (incentivado pela confiança e reconhecimento);

- Dar a mesma importância ao conhecimento em diferentes formatos;

- Incentivar o aprendizado e a criatividade;

- Focalizar o passado/presente e futuro;

- Reconhecer a importância da experimentação;

- Dar a mesma importância para a interface humana e tecnológica;

- Procurar formas de avaliação das iniciativas de conhecimentos realizados, tanto pela mensuração quantitativa como qualitativa

Sendo assim, as práticas de gestão do conhecimento são relacionadas, principalmente, aos aspectos de recursos humanos que facilitam a disseminação e o compartilhamento de informações e conhecimentos; as práticas ligadas aos processos organizacionais que funcionam como facilitadores de geração, retenção, organização e disseminação do conhecimento organizacional e, ainda, as práticas cuja base seja a tecnologia que serve de subsídio para a gestão do conhecimento (SANTOS, 2008, p. 202).

A preocupação com o tratamento do conhecimento produzido em ambientes organizacionais está entre as atividades da área da CI. A afirmação de que o objeto do campo da CI seria apenas a informação, já não mais condiz com a realidade das discussões existentes na área, o que é também comprovado em estudos realizados por pesquisadores e teóricos como Zins (2007). Os métodos, técnicas e ferramentas de GC se encontram em plena expansão nos ambientes organizacionais de todos os seguimentos econômicos. Dessa forma, as discussões direcionadas tanto à gestão da informação, quanto à gestão do conhecimento podem ser consideradas pertinentes no âmbito do campo científico da Ciência da Informação.

\section{LEI DE BRADFORT}

A Lei de Bradford possui características empíricas, e por cerca de 20 anos foi considerada apenas uma curiosidade estatística, porque não era expressa sob a forma de equação matemática, ou seja, não tinha base científica (COUTINHO, 1991, p. 170). 
Seu desenvolvimento teórico baseia-se na explicação de eventos probabilísticos que se juntam para criar um padrão regular de dispersão de artigos em distintos periódicos. Para tanto, é necessário, em primeiro lugar, descrever esse padrão matematicamente. Neste artigo, a Lei de Bradford foi aplicada na sua forma clássica para medir a produtividade absoluta, considerando-se o número de artigos publicados de acordo com as temáticas destacadas anteriormente. A Lei de Bradford verifica a dispersão da literatura a partir da identificação do núcleo de periódicos dedicados a um determinado assunto que, por sua vez, é formado por poucos títulos produtores de grande número de artigos de interesse. Esse núcleo se constitui na zona de produtividade número um de distribuição. Os outros periódicos, menos produtivos, em relação à temática são ordenados em zonas de produtividade decrescente de artigos sobre o assunto. $\mathrm{O}$ número de periódicos em cada zona aumenta à medida que sua produtividade individual diminui. $\mathrm{O}$ número de artigos em cada zona, no entanto, permanece mais ou menos constante.

De acordo com Brookes (1969) se periódicos científicos forem ordenados de maneira decrescente de produtividade de artigos, sobre determinado assunto, poderão ser divididos em um núcleo de periódicos mais particularmente dedicados ao assunto e, em vários grupos ou zonas, contendo o mesmo número de artigos que o núcleo. $\mathrm{O}$ número de periódicos (n), no núcleo e zonas subsequentes, variará na proporção 1:n:n². A Figura 1 apresenta a fórmula original da Lei de Bradford:

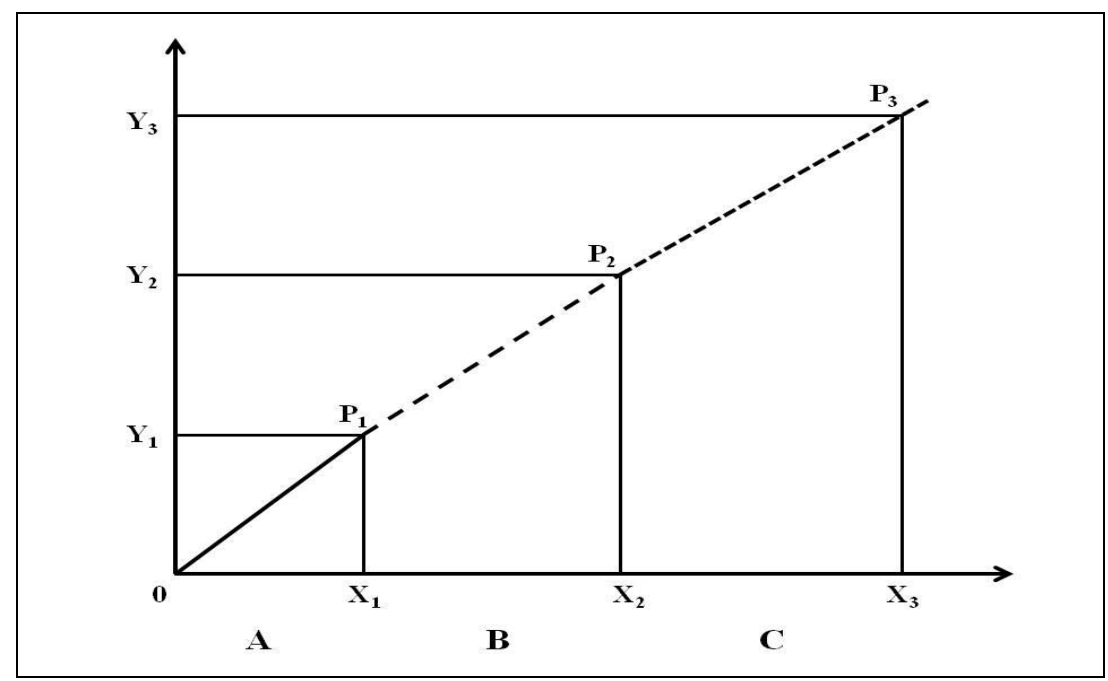

Figura 1. Lei de Bradford. Fonte: Ferreira - 2010.

Na Figura 1 estão representadas três zonas da fórmula original da Lei de Bradford. Explica-se que a Zona A corresponde à concentração; a Zona $B$ é correspondente à produtividade média e é a componente de Zipf (frequência de ocorrência de palavras); e a Zona $C$ compreende os periódicos de baixa produtividade - de dispersão e queda de Groos (PINHEIRO, 1982; 1983 apud FERREIRA, 2010, p. 5).

Brookes (1969) enumera algumas condições para a aplicação da Lei de Bradford: 
- O assunto da bibliografia, o tema, deve ser claramente definido;

- A bibliografia deve ser completa, incluir todos os periódicos relevantes;

- O período de tempo coberto deve ser suficientemente longo, a fim de que todos os periódicos tenham a mesma oportunidade de contribuir com artigos

A Lei de Bradford sugere que, na medida em que os primeiros artigos sobre um novo assunto são escritos para publicação em periódicos científicos, na maioria das vezes são submetidos a uma avaliação por pares e, se aceitos, atrairão outros artigos sobre a mesma temática, bem como no desenvolvimento do assunto na área. Também ocorrerá, ao mesmo tempo, a publicação de os primeiros artigos sobre o referido assunto em que outros periódicos da área. Caso o assunto continue a se desenvolver, emerge eventualmente um núcleo de periódicos que publicam sobre o tema, o que corresponde aos periódicos mais produtivos sobre o assunto, mais especificamente no que tange a quantidade de artigos publicados sobre a temática (GUEDES; BORSCHIVER, 2005, p. 4).

A Lei de Bradford pode ser aplicada em estudos bibliométricos de qualquer área do conhecimento e, também, como auxílio para o gerenciamento de sistemas de informação bibliográfica.

Ressaltam-se alguns dos trabalhos publicados que utilizaram a Lei de Bradford como aporte para a análise dos dados. Lima (1984) realizou um estudo para verificar a análise de citações, de 1978 a 1982, no periódico Scientometrics publicado em Amsterdam e especializado em Cientometria. Em 1991, Coutinho aplicou a Lei em um estudo na base de dados da Rede Ferroviária Federal S/A, analisando a distribuição segundo a origem e idioma dos artigos, destacando elementos que pudessem interferir na aplicação da Lei: periodicidade, forma de aquisição e falhas na coleção. No trabalho realizado por Gato et al. (2004) o foco foi o uso da coleção de periódicos, para evidenciar o papel fundamental que as bibliotecas da Empresa Brasileira de Pesquisa Agropecuária (EMBRAPA) desempenham na estrutura organizacional e na estratégia competitiva da empresa. Em um estudo mais recente Pinto, Igami e Bresssiani (2010) utilizaram a Lei para identificar o núcleo de revistas mais utilizado pelos pesquisadores do Instituto de Pesquisas Energéticas e Nucleares (IPEN) em relação à publicação de seus trabalhos.

Contudo ressalta-se que, dependendo da situação analisada, a aplicação da Lei de Bradfort sem maiores cuidados, pode levar a resultados pouco confiáveis, uma vez que o modelo atualmente disponível ainda é insuficiente para identificar o verdadeiro mecanismo do fenômeno.

\section{PROCEDIMENTOS METODOLÓGICOS}

A pesquisa, de natureza quantitativa, analisou as informações produzidas sobre as temáticas, gestão da informação e gestão do conhecimento, a partir dos artigos publicados em periódicos nacionais e internacionais da área de Ciência da Informação. Os procedimentos metodológicos adotados, para a coleta dos dados, foram definidos de acordo com os objetivos da pesquisa, os quais se centram na análise da produção científica relacionada à GI e à GC no âmbito da CI. 
Na primeira etapa, realizou-se um levantamento de todos os periódicos da área de CI, nacionais e internacionais, classificados no Qualis da Coordenação de Aperfeiçoamento de Pessoal de Nível Superior (CAPES). Destaca-se que o Qualis refere-se ao conjunto de procedimentos utilizados para estratificação da qualidade da produção intelectual dos programas de pós-graduação brasileiros, contemplando periódicos nacionais e internacionais. A classificação dos periódicos é feita a partir de critérios estabelecidos pela CAPES e são divididos em 8 (oito) estratos: A1; A2; B1, B2; B3; B4; B5; C, sendo 'A1' o estrato mais elevado e, portanto, com maior peso e ' $\mathrm{C}$ ' o menos elevado com peso zero. Esses indicadores estimulam os investigadores da área a publicarem nos periódicos que possuem classificação mais alta, determinando, portanto, quais os periódicos de maior relevância para a área. Nesse contexto, realizou-se um levantamento no Portal da CAPES $<$ http://www.capes.gov.br/index.php> com o intuito de identificar os periódicos da área de CI. O levantamento foi realizado no mês de julho de 2010 identificando 323 (trezentos e vinte e três) periódicos da área de CI relacionados no Portal da CAPES. Após análise dessa relação definiu-se como universo de análise os periódicos classificados nos estratos 'A' e 'B', e que se encontravam disponíveis online, totalizando 26 (vinte e seis) títulos de periódicos. Acredita-se que este recorte reflete a produção de artigos nos periódicos considerados mais relevantes para a área de CI no país, segundo a classificação da CAPES.

Na sequência, definiram-se os termos com os quais seriam realizadas as buscas: gestão da informação; information management; gestión de la información; gestão do conhecimento; knowledge management; gestión del conocimiento. A variação nos termos de busca foi necessária devido à diversidade das línguas publicadas nos referidos periódicos.

Durante o mês de agosto de 2010 foram efetuadas as buscas nas bases de dados online de cada um dos 26 (vinte e seis) periódicos selecionados. As bases foram acessadas através dos endereços eletrônicos de cada periódico. Na página inicial do periódico foi identificado o campo de busca e nele digitado as palavras-chaves definidas a priori. As buscas foram guiadas para que os termos pré-definidos fossem encontrados nos títulos, nas palavras-chaves e nos resumos de cada artigo. Dessa forma, os artigos recuperados continham os termos definidos a priori no título e/ou no resumo e/ou nas palavras-chave. Não foi delimitado o período para a busca, isso porque, no pré-teste realizado percebeu-se que o número necessário para a análise dos dados não seria suficiente. Desse modo, não foi indicado nenhum período de tempo para se realizar as buscas nas bases de dados e, assim, verificou-se que o artigo mais antigo recuperado é do ano de 2000. Após a coleta dos dados, os artigos foram registrados em tabelas e, posteriormente, aplicou-se a Lei de Bradford (1934), uma vez que esta possibilita a análise da produção científica de periódicos sobre determinada temática, observando a distribuição dos artigos em termos de variáveis de proximidade ou de afastamento, conforme foi detalhado anteriormente.

\section{APRESENTAÇÃO E ANÁLISE DOS DADOS}

Alguns pressupostos, propostos por Brookes (1969), para a aplicação da Lei de Bradford, podem justificar, em certa medida, o não ajustamento dos dados à distribuição 
ideal proposta por Bradford. O método para a análise que doravante se apresenta pode ser classificado como quantitativo-qualitativo por envolver os quesitos da formulação matemática de Bradford e sua interpretação sob a realidade observada a partir da pesquisa.

A seleção dos periódicos que correspondem à amostra foi não probabilística, ou seja, por conveniência, porém utilizando-se como direcionador o fato de que o índice Qualis, parâmetro para a seleção, é oficialmente reconhecido como critério de avaliação de periódicos pelos órgãos que regulam a atividade de formação em nível de pós-graduação no Brasil. Embora o assunto pesquisado seja bem definido, não é possível afirmar que todos os periódicos relevantes estejam indexados no Qualis. Esse risco, no entanto, confirma algumas suposições do próprio autor da Lei que considerava a possibilidade de haver certa dispersão na literatura no tocante a assuntos específicos. O fato de o tema pesquisado ser tratado por um grande número de periódicos, não especificamente dedicados ao assunto (à medida que se distancia do núcleo), aumenta o risco de haver um número representativo de periódicos não indexados que contemplem o assunto. $\mathrm{O}$ período pesquisado abrangendo de 2000 a 2010 é expressivo, se for considerado a perspectiva de que ofereceu a mesma chance de desenvolvimento do tema para todos os periódicos. No mesmo sentido que Guedes e Borschiver (2005) deram para seu levantamento teóricohistórico sobre Bibliometria, destacando que: "poucos autores produzem muito e muitos autores produzem pouco", tende a prevalecer. Os autores acrescentam que a Lei de Bradford permite estimar o grau de relevância, bem como quais são os periódicos que produzem o maior número de artigos sobre determinado assunto.

Os dados coletados, tabulados e analisados são apresentados a seguir, destacando as principais discussões e conclusões: 


\begin{tabular}{|c|c|c|c|c|c|c|}
\hline Qtd. & Periódicos & Qualis & $\mathbf{R}$ & $\mathbf{A}$ & $\mathbf{N P}$ & $\mathbf{P A}$ \\
\hline 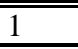 & Perspectivas em Ciência da Informação & A2 & 1 & 48 & 1 & 48 \\
\hline 2 & Ciência da Informação & $\mathrm{A} 2$ & 1 & 37 & 2 & 37 \\
\hline 3 & El Profesional de la Información & $\mathrm{A} 2$ & 1 & 36 & 3 & 36 \\
\hline 4 & DataGramaZero & $\mathrm{B} 2$ & 1 & 35 & 4 & 35 \\
\hline 5 & $\begin{array}{l}\text { The International Journal of Information Science } \\
\text { for Decision Making (Online) }\end{array}$ & B3 & 1 & 23 & 5 & 23 \\
\hline 6 & Informação \& Sociedade: Estudos & B1 & 1 & 21 & 6 & 21 \\
\hline $\begin{array}{l}7 \\
8 \\
\end{array}$ & \begin{tabular}{|l} 
Transinformação \\
Informação \& Informação (Online)
\end{tabular} & $\begin{array}{l}\text { B2 } \\
\text { B3 } \\
\end{array}$ & 2 & 15 & 8 & 30 \\
\hline $\begin{array}{l}9 \\
10\end{array}$ & $\begin{array}{l}\text { BID. Textos Universitaris de Biblioteconomia i } \\
\text { Documentació } \\
\text { Revista ACB }\end{array}$ & $\begin{array}{l}\text { B2 } \\
\text { B4 } \\
\end{array}$ & 2 & 12 & 10 & 24 \\
\hline $\begin{array}{l}11 \\
12\end{array}$ & $\begin{array}{l}\text { Investigación Bibliotecológica } \\
\text { Anales de Documentación (Online) }\end{array}$ & $\begin{array}{l}\text { B1 } \\
\text { B3 }\end{array}$ & 2 & 10 & 12 & 20 \\
\hline 13 & $\begin{array}{|lcc|}\text { Encontros Bibli: Revista Eletrônica de } \\
\text { Biblioteconomia e Ciência da Informação }\end{array}$ & B2 & 1 & 9 & 13 & 9 \\
\hline 14 & $\begin{array}{l}\text { Revista Digital de Biblioteconomia e Ciência da } \\
\text { Informação }\end{array}$ & B3 & 1 & 8 & 14 & 8 \\
\hline 15 & $\begin{array}{|lcc|}\text { Revista Brasileira de Biblioteconomia e } \\
\text { Documentação (Online) }\end{array}$ & B4 & 1 & 5 & 15 & 5 \\
\hline 16 & Brazilian Journal of Information Science & B3 & 1 & 4 & 16 & 4 \\
\hline $\begin{array}{l}18 \\
19 \\
20 \\
21\end{array}$ & \begin{tabular}{|l|} 
Revista de Biblioteconomia de Brasília \\
Revista Ibero-Americana de Ciência da \\
Informação \\
Arquivística.net \\
Revista de Ciências e Técnicas do Patrimônio \\
Ponto de Acesso
\end{tabular} & $\begin{array}{l}\text { B3 } \\
\text { B3 } \\
\text { B4 } \\
\text { B4 } \\
\text { B5 }\end{array}$ & 5 & 3 & 21 & 15 \\
\hline $\begin{array}{l}23 \\
24\end{array}$ & $\begin{array}{l}\text { Biblios: Revista de Bibliotecología y Ciencias de } \\
\text { la Información } \\
\text { Tendências da Pesquisa Brasileira em Ciência da } \\
\text { Informação } \\
\text { Liinc em Revista }\end{array}$ & $\begin{array}{l}\text { B2 } \\
\text { B3 } \\
\text { B3 }\end{array}$ & 3 & 2 & 24 & 6 \\
\hline $\begin{array}{l}25 \\
26\end{array}$ & $\begin{array}{l}\text { Información, Cultura y Sociedad } \\
\text { Prisma.com }\end{array}$ & $\begin{array}{l}\text { B3 } \\
\text { B5 }\end{array}$ & 2 & 1 & 26 & 2 \\
\hline 26 & TOTAIS & III & III & /II & 26 & 323 \\
\hline
\end{tabular}

Tabela 2. Distribuição de produtividade absoluta dos periódicos.

$\mathrm{R}=$ Produtividade dos periódicos: significa o volume de publicações de trabalhos sobre o tema gestão do conhecimento no título ou palavra chave.

$\mathrm{A}=$ Número de artigos: significa a quantidade média de artigos com base na produtividade que cada periódico publicou de autores sobre o tema gestão do conhecimento constante no título ou palavras chave.

$\mathrm{NP}=$ Número de periódicos ou produtividade acumulada: significa o volume de publicações de trabalhos sobre o tema gestão do conhecimento no título ou palavra chave de forma acumulada. 
PA= Produtividade de artigos: significa o total de artigos produzidos (publicados) nos periódicos sobre o tema gestão do conhecimento constante no título ou palavra chave.

A Tabela 2 demonstra que 26 (vinte e seis) periódicos contêm pelo menos um artigo sobre os termos pesquisados, totalizando 323 (trezentos e vinte e três) artigos encontrados no período pesquisado, ou seja, representa uma média de 12 (doze) artigos por periódico, se a distribuição fosse equitativa.

No entanto, segundo a Lei de Bradford é possível a distribuição da produtividade dos periódicos em zonas. Na formulação clássica haveria três zonas $(A, B, C)$ contendo um número aproximado de artigos. Entretanto, esse procedimento tenderia a gerar uma concentração em poucos periódicos que representam o núcleo da distribuição; as demais zonas correspondem a dispersão.

Observa-se ainda que, a produtividade dos periódicos $(\mathrm{R})$ em relação ao número de artigos (A), contendo os termos investigados, possui uma concentração enfatizando a máxima "poucos autores produzem muito e muitos autores produzem pouco", que é prevista pela maioria das leis aplicadas aos estudos bibliométricos. Para tanto, basta observar o volume de artigos em ordem decrescente produzidos por apenas 1 (um) periódico. Verifica-se também que a maioria dos periódicos que concentram a produtividade absoluta foi classificada como nível 'A' pela CAPES.

Para uma avaliação mais consistente aplicou-se a Lei de Bradford, visando à análise do ajustamento da distribuição anterior aos seus pressupostos.

\begin{tabular}{l|l|l|l}
\hline \hline $\mathbf{Z}$ & $\mathbf{R}$ & $\mathbf{A}$ & $\mathbf{m B}(\mathbf{k})$ \\
\hline Zona 1 & 3 & 121 & - \\
\hline Zona 2 & 9 & 153 & 3,00 \\
\hline Zona 3 & 14 & 49 & 1,56 \\
\hline Total & 26 & 323 & - \\
\hline \hline
\end{tabular}

Tabela 3. Distribuição dos artigos por zonas segundo a Lei de Bradford.

Nota: Multiplicador de Bradford ( $\mathrm{mB}$ (k) médio).

Observa-se, conforme apresentado na Tabela 3, que o multiplicador de Bradford $\mathrm{mB}$ (k) não representou uma constante, ou seja, há uma forte dispersão dos valores em cada zona em relação ao $\mathrm{mB}$ médio. Tal resultado é análogo - quando considerado o aspecto assimetria e dispersão -, conforme encontrou Machado (2007) ao investigar 16 (dezesseis) anos de publicações com a temática Bibliometria no Brasil (1990-2005).

Machado (2007) demonstra que as publicações envolvendo estudos sobre a temática por ele investigada é bastante assimétrica variando de 1 (um) a 6 (seis) publicações anuais divididas entre os seis periódicos pesquisados.

Isso se deve ao fato de que há uma forte concentração de artigos no núcleo e na primeira zona de dispersão se comparadas com a zona 3 (três), significando que os termos pesquisados ainda não estão em estágio muito elevado de maturação, considerando-se a 
produção de artigos em periódicos. Não se trata da vinculação exclusiva da maturação de determinado campo científico, ao número de trabalhos contendo os termos a ele referenciado. Contudo, sob o ponto de vista bibliométrico o volume de publicações passa a ser a variável principal levando à concepção de maturação da utilização e discussão de determinadas expressões e terminologias que poderão ou não contribuir para a maturação do próprio campo.

Acredita-se, por exemplo, que à medida que essas temáticas forem se tornando mais estudadas e conhecidas, além de aumentar o volume de artigos no núcleo, também ocorrerá uma maior dispersão de publicações em periódicos que ainda não estão sendo contempladas. Por isso Brookes (1969) alerta sobre a necessidade de consideração de um período de tempo razoável.

\begin{tabular}{l|l|l}
\hline \hline Z & R & MB(k) \\
\hline Zona 1 & 3 & - \\
\hline Zona 2 & 7 & 2,28 \\
\hline Zona 3 & 16 & 2,28 \\
\hline Total & 26 & - \\
\hline \hline
\end{tabular}

Tabela 4: Distribuição ideal de Bradford.

Nota: Distribuição ideal de Bradford - I:n: $n^{2}$.

Aplicou-se de forma ilustrativa o multiplicador de Bradford (Tabela 4), encontrado na primeira distribuição como parâmetro de redistribuição dos periódicos. Desse modo, se a distribuição do número de periódicos seguisse a proporção prevista pela referida Lei haveria uma maior concentração de periódicos na área de dispersão (16) do que a observada pela aplicação anterior (14), porém não haveria modificação substancial na distribuição dos artigos.

Como foi utilizada a formulação clássica da $L e i$, era previsível que o ajuste não fosse perfeito, uma vez que $n$ variáveis influenciam a distribuição empírica da literatura. Essas variáveis não são captadas pela fórmula clássica de Bradford, e representam o maior desafio para os estudiosos contemporâneos de sua formulação matemática. Um estudo mais detalhado exigiria, por exemplo, que fossem consideradas algumas variáveis como, por exemplo, a periodicidade, o número de páginas, o número de artigos etc., isto é, seria importante encontrar a produtividade relativa para os periódicos analisados antes da aplicação da Lei.

O núcleo é formado pelos seguintes periódicos científicos: Perspectivas em Ciência da Informação, Ciência da Informação e El Profesional de la Información, pois representam $12 \%$ do total pesquisado e são responsáveis por $37 \%$ dos artigos publicados, confirmando os pressupostos de Brookes (1969).

A identificação do núcleo de periódicos é um dos objetivos dos estudos bibliométricos que, conforme Guedes e Boschiver (2005), entre outros aspectos é importante para o planejamento, avaliação e gestão da ciência e tecnologia. 
O núcleo apontado a partir da aplicação da Lei de Bradford reconhece perfeitamente um importante aspecto relativo ao comportamento acadêmico científico, ou seja, quando há a evidência de que determinado periódico é ou terá reconhecimento no meio, mais e mais publicações são a ele direcionadas. Guedes e Borschiver (2005) enfatizam que a partir da aplicação da metodologia de Bradford os periódicos formam um núcleo de periódicos que supostamente indicam serem os de maior qualidade ou relevância para determinada área.

Tal comportamento acaba incentivando um ciclo que manterá o núcleo em evidência e concentrando mais e mais publicações, até que por saturação ou rearranjo natural se inicie o processo de dispersão. Machado (2007) corrobora com os resultados aqui apresentados, por exemplo, quando ressalta que o periódico Ciência da Informação aglutinou mais de $70 \%$ dos artigos por ele selecionados, e que de fato está presente no núcleo obtido por este estudo. Cabe aqui a ressalva sobre a possibilidade de interferências importantes das variáveis: escopo de pesquisa, área de interesse, objetivos etc. quanto aos aspectos quantitativos, portanto, análises mais aprofundadas necessitariam incluir tais variáveis. Não obstante os resultados apontam tanto a existência de um núcleo de periódicos, quanto à assimetria como fatores característicos do quadro de publicações sobre os temas pesquisados.

Nessa perspectiva, é o que Santos e Kobashi (2009) resgatam em sua revisão teórica, destacando a possibilidade de um periódico poder gerar monopólio, por meio do efeito núcleo por um lado, ou por outro, o que seria um constante desafio da Ciência: causar o efeito dispersão pela constante abertura à novidade supervisionada.

A expectativa de abertura à novidade talvez seja a maior contribuição do apontamento do comportamento das publicações nos principais periódicos sobre determinados temas em áreas específicas. Qualquer ação, ou antes, ainda, qualquer planejamento de políticas no sentido de influenciar a prática científica deve ter em mente não apenas a concentração, o mais do mesmo, mas a abertura de possibilidades ao novo.

A análise até aqui apresentada demonstra que as publicações envolvendo os termos investigados oferecem um largo espaço de reflexão, para a possibilidade de abertura de canais de discussões envolvendo revisões temáticas de periódicos e eventos da área de Ciência da Informação sempre no sentido da expansão vigiada que caracteriza a evolução da Ciência.

O trabalho de Santos e Kobashi (2009) indica, a partir da descrição do comportamento dos trabalhos de caráter quantitativo, um horizonte no qual a Ciência provavelmente passará a se repensar no que se refere à distribuição quanti e qualitativa de suas publicações. Consideram entre outras, que: i) os estudos quantitativos vêm passando gradativamente da contagem para a interpretação; ii) os estudos cienciométricos se aproximam cada vez mais das ciências moles; iii) os estudos sobre o conteúdo dos trabalhos vem ganhando espaço em detrimento daqueles com foco exclusivamente quantitativo. 


\section{CONSIDERAÇÕES FINAIS}

A Lei de Bradford representa um importante parâmetro de análise de dispersão de publicações, independentemente do ajustamento e de sua confirmação empírica.

O fato de se observar o não ajustamento dos dados à distribuição ideal, permite-nos a reflexão sobre as possíveis causas e o conhecimento sobre as características dos termos pesquisados.

Os termos 'gestão da informação' e 'gestão do conhecimento' podem ser considerados contemporâneos e, ao longo do tempo, certamente levarão a uma distribuição mais ajustada, conforme propôs Bradford e demais autores estudiosos deste assunto, uma vez que a maturidade das pesquisas representa outra importante variável para os estudos sobre dispersão de literatura.

Cabe, ainda, uma importante constatação: se há a concentração em poucos periódicos, e esses foram os classificados como de nível 'A' pela CAPES, pode-se considerar que, em certa medida, os critérios de classificação de periódicos em relação a determinadas áreas ou temas podem estar vinculados a aspectos quantitativos de produção. Leva-nos a refletir sobre a necessidade de análises mais profundas e qualitativas que comprovem o posicionamento dos periódicos em relação aos aspectos de produtividade.

Sugere-se que outras pesquisas apliquem a Lei de Bradford, a partir da produção relativa e incorporando novas variáveis que possibilitem análises mais aprofundadas.

Os três periódicos contemplados no núcleo desta pesquisa, no entanto, representam espaços já consagrados no ambiente acadêmico-científico e justificam a concentração observada.

\section{REFERÊNCIAS}

BARBOSA, R.R. Gestão da informação e do conhecimento: origens, polêmicas e perspectivas. Informação \& Informação, 2008, vol. 13, n esp, p. 1-25. Disponível em: <www.uel.br/revistas/uel/index.../informacao/.../1843>. [Consulta: 15 de maio de 2011].

BEAL, A. Gestão estratégica da informação: como transformar a informação e a tecnologia da informação em fatores de crescimento e de alto desempenho nas organizações. São Paulo: Atlas, 2008.

BRADFORD, S.C. Sources of Information on scientific subjects. Engineering, 1934, $\mathrm{n}^{\mathrm{o}}$ 137, p. 85-86.

BROOKES, B.C. Bradford's law and the bibliography of science. Nature, 1969, $\mathrm{n}^{\circ}$ 222, p. 953-956.

COUTINHO, E. Aplicação da lei de Bradford à literatura técnica sobre ferrovia: análise de periódicos e avaliação da base de dados da Rede Ferroviária Federal S.A. Ciência da Informação, 1991, vol. 20, $\mathrm{n}^{\mathrm{o}}$ 2, p. 169-180. Disponível em: <revista.ibict.br/ index.php/ciinf/article/download/1252/892>. [Consulta: 25 de agosto de 2011]. 
DAVENPORT, T. y PRUSAK, L. Ecologia da informação: por que só a tecnologia não basta para o sucesso na era da informação. São Paulo: Futura, 1998.

FERREIRA, A.G.C. Bibliometria na avaliação de periódicos científicos. DataGramaZero,- vol. 11, no 3, p. 1-13. Disponível em: <http://www.dgz.org.br/ jun10/Art_05.htm>. [Consulta: 25 de agosto de 2011].

GATO et al. Gestão da informação na Embrapa Amazônia Oriental: uso relativo versus uso efetivo da literatura técnico-científica agropecuária periódica - 1990-1999. Ciência da Informação, 2004, vol. 33, nº 2, p. 83-90.

GUEDES, V. y BORSCHIVER, S. Bibliometria: uma ferramenta estatística para a gestão da informação e do conhecimento, em sistemas de informação, de comunicação e de avaliação científica e tecnológica. In: Proceedings CINFORM - VI Encontro Nacional de Ciência da Informação. Salvador - Bahia, 2005.

LEITE, F.C.L. Comunicação científica e gestão do conhecimento: enlaces conceituais para a fundamentação da gestão do conhecimento científico no contexto de universidades. Transinformação, 2007, vol. 19, nº 2, p. 139-151.

LIMA, R.C.M. Estudo bibliométrico: análise de citações no periódico "Scientometrics". Ciência da Informação, 1984, vol. 13, nº 1, p. 57-66.

MACHADO, R.N. Análise cientométrica dos estudos bibliométricos publicados em periódicos da área de biblioteconomia e ciência da informação (1990-2005). Perspectivas em Ciência da Infromação, 2007, vol. 12, nº 3, p. 2-20.

SHERA, J.H. Sobre Biblioteconomia, Documentação e Ciência da Informação. In: GOMES, H. E. (Org.). Ciência da informação ou informática? Rio de Janeiro: Calunga, 1980, p. 91-105.

PINTO, A.L.; IGAMI, M.P.Z. y BRESSIANI, J.C. Visibilidade e monitoramento científico na área nuclear e ciências relacionadas: uma perspectiva a partir da produtividade do IPEN-CNEN/SP. Perspectivas em Ciência da Informação, 2010, vol. $15, \mathrm{n}^{\circ} 2$, p. 198-218.

PONJUÁN DANTE, G. Gestión de información en las organizaciones: princípios, conceptos y aplicaciones. Santiago: CECAPI, 1998.

PONJUÁN DANTE, G. Gestión de información: dimensiones e implementación para el êxito organizacional. Rosario: Nuevo Parhadigma, 2004.

ROSSEAU, J.I. y COUTURE, C. O lugar da arquivística na gestão da informação. In: Os fundamentos da disciplina arquivística. Lisboa: Dom Quixote, 1998, p. 61-76.

SANTOS, V.B. dos. A prática arquivística em tempos de gestão do conhecimento. In: (Org.). Arquivística: temas contemporâneos: classificação, preservação digital e gestão do conhecimento. 2. ed. Brasília: SENAC, 2008, p. 175-223.

SANTOS, R.N.M. dos y KOBASHI, N.Y. Bibliometria, cientometria, infometria: conceitos e aplicações. Tendências da Pesquisa brasileira em Ciência da Informação, 2009, vol. 2, no 1, p. 155-172.

SILVA, S.L. da. Informação e competitividade: a contextualização da gestão do conhecimento nos processos organizacionais. Ciência da Informação, vol. 31, $\mathrm{n}^{\mathrm{o}} 2$, p. 142-151, maio/ago. 2002. Disponível em: <http://www.scielo.br/pdf/ci/v31n2/ 12917.pdf>. [Consulta: 10 de junho de 2011]. 
VALENTIM, M.L.P. Informação e conhecimento em organizações complexas. In: (Org.). Gestão da informação e do conhecimento no âmbito da Ciência da Informação. São Paulo: Polis Cultura Acadêmica, 2008, p. 11-25.

VALENTIM, M.L.P. Gestão da informação e gestão do conhecimento: especificidades e convergências. Londrina: Infohome, 2004. Disponível em: $<$ http://www.ofaj.com.br/colunas_conteudo.php?cod=88>. [Consulta: 10 de janeiro de 2010].

ZINS, C. Conceptions of Information Science. Journal of the American Society for Information Science and Technology, 2007, vol. 58, nº 3, p. 335-350. 